\title{
ALGUMAS REFLEXÕES SOBRE OS CONTEÚDOS DE HISTÓRIA ANTIGA NOS LIVROS DIDÁTICOS BRASILEIROS
}

Gilvan Ventura da Silva"

Ana Teresa Marques Gonçalves"

RESUMO:

Este artigo pretende discutir alguns aspectos do modo pelo qual os conteúdos de História Antiga são tratados nos livros didáticos brasileiros. De início, constatamos que existe uma acentuada separação entre os espaços da sala de aula e da Universidade, de modo que o saber produzido por esta última não é sistematicamente difundido nos livros didáticos escolares. Tal problema, aliado à ausência de especialistas em História Antiga nas equipes que confeccionam os liveros didáticos, contribui para uma qualidade de ensino extremamente precária quando se trata da Antiguiidade, aí incluída a Pré-História. O resultado é a perpetuação nos livros de inúmeras simplificações de conteúdo que comprometem, algumas vezes de modo irremediável, o trabalho pedagógico desenvolvido.

UNITERMOS: História Antiga, Livro Didático, Educação.

O trabalho com o Livro Didático, tanto no Ensino Fundamental quanto no Médio é, como se sabe, uma atividade que exige um cuidado permanente por parte dos professores no sentido de converter o material em questão em um instrumento pedagógico eficiente e efetivamente formador. Essa tarefa, embora

\footnotetext{
Doutor em História Antiga - Professor de História Antiga da UFES

Mestre e Loutoranda em História Antiga - Professora de História Antiga e Medieval da UFC.
} 
possa parecer à primeira vista bastante óbvia, não é menos desafiadora na medida em que os livros didáticos à disposição no mercado editorial brasileiro, salvo raras e honrosas exceções, apresentam uma quantidade tal de deficiências que por vezes inviabilizam a sua utilização. De fato, não causaria estranheza a nenhum educador a constatação de que os nossos livros didáticos se encontram, em termos gerais, abaixo das expectativas quando se trata de fornecer ao aluno um ensino de qualidade em função dos erros, anacronismos, desatualizações e juízos de valor que tais publicações comportam. Essa situação se torna particularmente grave se levarmos em consideração o fato de que o livro didático em inúmeras escolas ao longo desse País é o único material bibliográfico disponível para consulta de alunos e professores, o que aumenta sobremaneira as responsabilidades dos autores e editores na sua elaboração. Naturalmente que nenhuma publicação, seja de que tipo for, está isenta de reparos ou acima da crítica. No entanto, do modo como o sistema educacional brasileiro hoje se estrutura, é imprescindível que o livro didático possibilite ao professor desenvolver um ensino de qualidade, sob pena de produzir-se uma deformação que acompanhará o aluno até, quem sabe, a Universidade.

Na verdade, na medida em que os professores não costumam receber uma formação adequada em determinadas áreas do conhecimento que ensinam durante a Licenciatura, isso contribui para uma sensível diminuição da sua capacidade crítica, problema agravado pelo fato de que são poucos os professores de Ensino Fundamental e Médio que após terem obtido habilitação para lecionar prosseguem a sua capacitação por intermédio de cursos de pós-graduação e/ou atualização.

Tal afirmação, embora possa parecer um truísmo, não o é se observarmos a péssima cualidade dos livros didáticos de História à disposição no mercado. A grande interrogação seria: 
por que essas obras são tão deficientes se congregam uma quantidade considerável de profissionais na sua execução, muitos deles com renome nacional? Uma das explicações possíveis seria, em nosso entender, a formação deficiente do próprio professor, o yual não possui condições efetivas de liscriminar entre um livro didático ruim, um médio e um sattisfatcirio. Quanto a isso, é importante frisar que muitas vezes () yue o livro traz não é sequer o conhecimento acadêmico adaptado de modo bastante simples à capacidade cognitiva dos alunos, mas o senso comum na sua mais estrita acepção, e é isso cue infelizmente acaba se constituindo em matéria de ensino dadas as limitações do profissional. Se o professor possuísse preparo suficiente para dialogar com o Livro Didático sem se prender a esquemas explicativos cristalizados e conteúdos já superados, então o livro, mesmo comportando imprecisóes e equívocos, como de resto qualquer outra obra literária, se transformaria em um poderoso instrumento pedagógico à disposição dos nossos professores. Além disso, pela yuantidade de erros, anacronismos e desatualizações presentes nos Livros Didáticos, torna-se evidente que, em muitos casos, as equipes que formulam tais coleções não são compostas por professores especializados em História Antiga. Sahemos que é muito mais fácil criticar os livros didáticos existentes do que confeccionar um. Porém, inúmeros problemas hoje detectáveis poderiam e deveriam ser evitados recorrendo-se a especialistas em História Antiga para integrar as equipes que produzem o manuais didáticos ou, ao menos, avaliar a obra já pronta.

Para utilizar o Livro Didático com maior perícia e autonomia, seria necessário no entanto que o professor (nos referimos aqui ao professor de História em particular) tivesse recebido uma formação superior minimamente satisfatória. A História, assim como os demais saberes acadêmicos, é um 
domínio de conhecimento verdadeiramente monumental. Um licenciado em História atualmente deve ter condições de transitar do Paleolítico até a Queda do Muro de Berlim com o mínimo de competência o que, reconheçamos, não é uma tarefa muito fácil. Nesse sentido, a sua formação superior deveria, ao menos em tese, ter contemplado todas as grandes áreas nas quais os departamentos de História das Universidades e Faculdades brasileiras tradicionalmente se subdividem. No entanto, por uma série de razões que não nos cabem aqui discutir, algumas áreas do conhecimento histórico cujo ensino é obrigatório por determinação do Conselho Superior de Educação e que fazem parte do currículo mínimo das escolas de nível fundamental em muitos estados brasileiros, são tratadas de modo absolutamente indigente, resultando na formação de profissionais despreparados. Dentre essas áreas, parece-nos que a mais prejudicada é sem dúvida a de História Antiga e Medieval, incluindo aí a Pré-História. Como resultado direto dessa falta adequada de formação por parte dos licenciandos, não nos surpreende a constatação de que nos Livros Didáticos os conteúdos referentes à História Antiga e Medieval sejam os que padecem da maior quantidade de problemas, alguns dos quais bastante sérios, a ponto de comprometer a própria validade daquilo que está sendo ensinado.

Todo esse quadro é sem dúvida agravado pelo fato de que, em nossa sociedade, a escola não é concebida como um local de produção de conhecimento, mas apenas de difusão de um saber constituído en outras instâncias, principalmente na Universidade. À Academia competiria a realização de pesquisas e a geração do conhecimento propriamente dito; à escola caberia a reprodução do saber já constituído. No que diz respeito aos conteúdos de História Antiga, entretanto, nem mesmo esta relação tem se estabelecido de modo satisfatório. Uma leitura atenta realizada em alguns livros didáticos de 
História publicados no País é suficiente para nos convencer de que os mesmos não têm passado por revisões periódicas de conteúdo, não acompanhando assim as novas descobertas arqueológicas e as novas tendências de conceituação aplicadas à documentação, quer literária quer iconográfica, disponível.

Como os professores de ensino fundamental encontramse, de um modo geral, afastados das instâncias universitárias, conforme mencionamos, os mesmos não conseguem detectar os problemas de defasagem de conteúdo que se repetem nos livros didáticos. Postos à margem da produção do saber histórico, os professores do Ensino Fundamental e Médio não buscam, muitas vezes, acompanhar as discussóes recentes acerca da produção científica na sua área por meio de leituras mais recentes, o que os leva a submeterem-se passivamente ao saber condensado nos livros didáticos (LIMA, 1998, p. 196). Como afirma Bárbara Freitag (1989, p. 124), o livro didático não é visto como um instrumento de trabalho auxiliar na sala de aula, mas sim como a autoridade, a última instância, o critério absoluto de verdade, o padrão de excelência a ser adotado na aula. Entretanto, tudo isto ainda seria válido, mesmo visando à reprodução do saber e não à sua construção, se este conteúdo estivesse atualizado. Como os conteúdos de História Antiga são repetidos amiúde do mesmo ao longo de várias coleções e estas por sua vez, ao se constituírem, se fundamentam em manuais mais antigos, as desatualizações vão se perpetuando ao longo do tempo de modo quase mecânico.

Nas coleções de História, podemos perceber duas tendências principais ao se estruturar o conteúdo de História Antiga: ou se tenta abranger de forma panorâmica todas as civilizaçôes antigas orientais e ocidentais ou, buscando aproximar o mundo contemporâneo do passado, remete-se o aluno a uma procura das origens de certas instituições atuais, ressaltando-se o valor das civilizações grega e romana, 
principalmente. No primeiro caso, ao se tentar abranger um domínio tão amplo, as informações se perdem no contexto geral. Lembramo-nos do volume de uma coleção, dedicado à quinta série, no qual a civilização persa era tratada em três parágrafos, a civilização chinesa em cinco parágrafos e a japonesa em quatro parágrafos. Dessa forma, o aluno apenas é informado acerca da existência destas sociedades em lugar de estudá-las e de buscar compreendê-las. Acreditamos que uma opção mais razoável seria analisar um conteúdo menos extenso, mas de forma mais aprofundada, o que por outro lado não é algo menos complicado.

De fato, muitos dos livros que optam por esta estratégia acabam por incentivar o aluno a empreender uma verdadeira busca às origens do que existe atualmente. Vêem-se as origens do teatro na Grécia, do direito em Roma, da democracia no mundo grego clássico, da reforma agrária na República Romana, como se o yue existe hoje fosse um mero prolongamento do que houve no passado. Fazem-se estas comparações sem se perceber que o teatro na Grécia tinha um sentido político próprio e muito especial para o povo grego, inclusive de caráter religioso; que o direito romano foi sendo muito modificado ao longo do tempo, selecionado em suas várias vertentes, principalmente a partir da releitura que the foi imposta no Renascimento; que o conceito de democracia ateniense era completamente diverso do aplicado atualmente (FINLEY, 1988); que a tentativa de reforma agrária proposta pelos irmãos Gracos respondia a anseios específicos e apresentava uma dinâmica diversa da dinâmica contemporânea (CORASSIN, 1988); e que a escravidão antiga possuía igualmente as suas particularidades, não contendo em si nenhuma questão racial e comportandu agentes sociais impensáveis para o mundo moderno, como a do liberto romano. ${ }^{1}$

\footnotetext{
1 Para maiores detalleses, consultar Finley (1991); Giardina (1992); Vernant e Vidal Nilunuet (1989).
} 
Afora os equívocos de ordem didática e metodológica, alguns dos quais imperdoáveis e por isso mesmo facilmente detectáveis, os Livros Didáticos apresentam com maior freqüência um tipo particular de limitação que compromete sobremaneira a sua qualidade: as chamadas simplificações. Quando tratamos de simplificações, é preciso esclarecer de antemão que é da própria natureza do Livro Didático simplificar, ou seja, adaptar um determinado conteúdo mais complexo à capacidade cognitiva do aluno, o que muitas vezes requer a supressão de detalhes e desdobramentos suplementares de um dado processo para reter as suas características gerais de modo a facilitar a sua compreensão por parte do estudante. Ser capaz de realizar uma operação como essa é, sem dúvida, um dos maiores desafios dos nossos educadores. Isso não se confunde, no entanto, com as simplificações das quais tratamos aqui, ou seja, aquelas que com a pretensão de facilitar o processo de ensino/aprendizagem trata os conteúdos ensinados com tal negligência que termina por distorcê-los. No decorrer da nossa experiência como professores universitários de História Antiga, procuramos sempre realizar com os alunos a crítica do Livro Didático. Como resultado desse trabalho, elaboramos de modo preliminar uma tipologia que pudesse dar conta das múltiplas simplificações contidas nos Livros Didáticos e com isso facilitar a nossa investigação. Sendo assim, poderíamos dizer que grosso modo as simplificações detectáveis nos Livros Didáticos são de cinco tipos: a) simplificações processuais; b) simplificações teórico-conceituais; c) simplificações comparativas; d) simplificações valorativas e e) generalizações espaço-temporais. Vejamos como cada uma delas se apresenta.

Por simplificações processuais, entendem-se aquelas explicações que, ao resumirem em demasia um determinado processo histórico, terminam por descaracterizá-lo, produzindo 
assim uma caricatura. Dentre todos os tipos de simplificação contidas nos Livros Didáticos, esta é a mais recorrente. Um exemplo bastante sugestivo de como as simplificações processuais se apresentam nos é fornecido pelo pressuposto de que a invenção da agricultura e do pastoreio representou a adoção de uma nova forma de vida bastante distinta daquela dos caçadores-coletores, quando sabemos que o sedentarismo e a Revolução Neolítica não alteraram de imediato os padrões de organização social herdados do Paleolítico. Não obstante as inovaçôes trazidas com a domesticação de plantas e animais, o fato é que as sociedades do Neolítico continuam a fundamentar a distinção entre os indivíduos a partir do parentesco, do sexo e da idade. Somente o surgimento do Estado produzirá uma alteração social de maior envergadura. Além disso, é preciso considerar que o domínio sistemático sobre a produção de alimentos não foi suficiente para suprimir a pesca, a caça e a coleta herdadas do período anterior. Sendo assim, uma explicação da passagem do Paleolítico para o Neolítico como aquela veiculada pelos Livros Didáticos simplifica a tal ponto o processo que termina por atribuir-lhe uma dimensão que o mesmo não possui efetivamente.

No que concerne às simplificaçóes conceituais, os problemas são tão ou mais graves. Isso porque, salvo alguns casos específicos, os autores de livros didáticos não possuem uma preocupação estrita com a reflexão prévia acerca dos termos e conceitos que utilizam, o que nos causa estranheza se nos recordamos que boa parte do trabalho de reflexão intelectual dos historiadores é consumida na tentativa de definir por intermédio de conceitos os mais precisos possíveis as relações sociais que compõem os objetos que estudam. Sem os conceitos (ou os invariantes na acepção de Paul Veyne, cf. 1989), perpetuamos a antiga História dos tratados e batalhas, o que os 
historiadores há muito já trataram de abolir do seu ofício. Nos livros didáticos, entretanto, o assunto não adquire maior relevo. Desse modo, ou os conceitos são empregados sem nenhuma definição, quase como se fossem auto-explicativos, ou a definição) que thes é dada pelos autores é tão genérica que os mesmos acabam por ter o seu potencial significativo diluído. Assim ocorre, por exemplo, quando encontramos uma definição de feudalismo como se segue: "forma de organização social baseada nas relações de trabalho em tomo da terra e da produção exclusivamente rural". A rigor, qualquer sociedade agrária, feudal ou não, se estrutura a partir das relações de trabalho com a terra, de maneira que a explicação do conceito contribui muito pouco para esclarecer a especificidade do feudalismo. Um problema semelhante se verifica quando o capitalismo é entendido como um "sistema que se baseia no lucro e na exploração do homem pelo homem" o que, convenhamos, não quer dizer muita coisa.

Em algumas situações, observamos também a utilização de conceitos que há muito já foram superados ou redefinidos pela historiografia, como ocorre, por exemplo, com o célehre conceito de "decadência", o qual reina em nossos livros didáticos de forma praticamente absoluta quando se trata de explicar a crise do Império Romano do Ocidente. Apesar de sua utilização vir sofrendo, desde pelo menos a década de ' 80 , severas críticas por parte dos meios acadêmicos, o que inclusive resultou na elaboração de um verbete específico sobre o assunto, de autoria de Jacques Le Goff (1994, p. 375-422), para a Enciclopédia Einaudi no qual este autor apresenta argumentos decisivos para se repensar a utilização do conceito na explicação de fenômenos globais de transformação e propõe a sua substituição pelo conceito de "desagregação", o conceito de "decadência" ainda ocupa uma posição de preeminência no repertório explicativo dos nossos livros didáticos. 
Outro conceito que se repete à exaustão, em que pese a sua revisão já ter sido proposta por inúmeros historiadores, incluindo os brasileiros que trabalham com o materialismo histórico, é o de Modo de Produção Asiático conjugado com a famosa Hipótese Causal Hidráulica, empregada em inúmeros manuais para explicar o aparecimento das primeiras cidades na zona aluvional do Crescente Fértil. No livro Modo de Produção Asiático: Nowa Visita a um Velho Conceito, historiadores de referência para o estudo do mundo antigo no Brasil, como Ciro Flamarion S. Cardoso e Emanuel Bouzon, defendem a idéia de que não é válido se querer derivar a Civilização, em seus primórdios e em certas regióes do mundo, de um fator monocausal, ou seja, a necessidade de um controle centralizado tanto do abastecimento de água quanto da proteção contra as inundações em zonas áridas ou semiáridas. Esse determinismo simplista, ao mesmo tempo geográfico e técnico, presente nas formulações iniciais de Marx e Engels, não pôde sustentar-se ao ser transformado em hipótese de trabalho submetida a suficiente confrontação empírica. $\mathrm{Na}$ verdade, tal hipótese revelou-se falsa em todos os casos estudados (CARDOSO, 1990, p. 121-2), o que não a impede de ainda permanecer como válida em muitos dos nossos manuais. ${ }^{2}$

Un terceiro grupo de simplificações é constituído pelas comparações espúrias e desnecessárias que se estabelecem entre sociedades distintas no tempo e no espaço. Evidentemente que

\footnotetext{
2 Em se tratando de conceitos, o yue dizer da "plebe" romana? Como o mesmo termo "plebe" é usade para significar grupos sociais diversos durante a República co Império, o aluno fica sem entender o que foi a questão patrícioplebéia. Tal questáa aparece sempre como uma luta travada entre pobres e ricos, quando o que estava em discussão eram questoes políticas mais do que economicas. A plebe no período da Realeza e nos primóndios la República era formada por grupos sociais muito diversos dos que viriam a compô-la no períoto imperial, e isto não é expresso em quase nenhum livro didático existente, possivelmente poryute nem os autores conhecem desta diferença.
} 
os procedimentos que envolvem a História Comparada são absolutamente meritórios e recomendáveis, desde que os critérios de comparação não induzam o aluno a concluir pela existência de semelhanças e/ou diferenças inexistentes. É preciso, antes de tudo, muita cautela com as comparaçóes propostas, inclusive com o intuito de evitar anacronismos, um dos equívocos mais graves em se tratando do conhecimento histórico. Comparar realidades muito distantes no tempo e no espaço requer ainda um cuidado redobrado, pois no esforço de tentar tornar mais inteligível para os estudantes contemporâneos processos muito recuados no tempo mediante a comparação com elementos do cotidiano podem ser cometidas sérias distorções. Um caso exemplar do que afirmamos é o do Livro Didático que, ao pretender facilitar a compreensão do sentido histórico das pinturas rupestres, afirmava que as mesmas resultavam de um desejo dos homens pré-históricos em "marcar presença", assim como se comportam os adolescentes de hoje ao escreverem o seu nome nos muros e monumentos. Tal comparação é simplesmente um absurdo, dispensando maiores comentários.

Lembramo-nos ainda de um livro didático no qual se tentava estabelecer a todo custo uma comparação simplista e anacrônica entre a força hélica romana e a força bélica norteamericana, sem se levar em consideração qualquer tipo de diferenciação entre elas. Ao final do exercício proposto ao aluno, a única conclusão possível era a de que os Estados Unidos atuais nada mais são que a reencarnação do Império Romano, sem se levar em consideração formas de dominação tão distantes no tempo e no espaço e tão díspares na forma de se realizarem e nos propósitos a serem alcançados. Consultese, por exemplo, o competente estudo feito por Norberto Guarinello (1987) em uma obra paradidática a respeito da noção de "Imperialismo", diferenciando o imperialismo grecoromano de fenomenos similares no mundo moderno e 
contemporâneo. Trata-se do mesmo termo, mas com sentidos diferentes no tempo e no espaço. Na imensa maioria de nossos livros didáticos, infelizmente, tais distinções ainda não são explicitadas.

O conhecimento do passado mais distante é, como se sabe, de fundamental importância para a compreensão do presente, mas tal conhecimento não deve ser encerrado apenas neste caráter utilitário. Este passado deve ser analisado a partir de seu próprio instrumental de análise. Muitas vezes, para se despertar o interesse dos alunos, pode-se (e até mesmo devese) começar o estudo de una civilização como, por exemplo, a mesopotâmica, a partir do que ela tem de exótico ou, ao contrário, de parecido com o tempo atual, como a confecçáo de horóscopos pelos caldeus. Destarte, não se pode ficar apenas nisto. No caso específico do estudo da Mesopotâmia é fundamental explorar com us alunos o conceito de CidadeEstado, o yual reaparecerá no estudo da Grécia Antiga, do mundo romano, e mesmo no estudo das Cidades-Estados modernas, como Florença e Gênova, entre outras (CARDOSO, 1987).

Ao se relatar as experiências do passado, são poucuússimos os livros didáticos nos quais se atenta para o fato de que muitos dos fatos narrados nas diversas civilizações apresentadas, ocorreram de forma simultanea. O mais recorrente é que se abram capítulos para cada uma das civilizações. Por exemplo, surgimento, desenvolvimento e crise da civilização egípcia; surgimento, desenvolvimento e crise da civilização mesopotâmica; surgimento, desenvolvimento e crise da civilização grega; surgimento, desenvolvimento e crise da civilização romana. Como se estas sociedades não tivessem interagido entre si. São postas como blocos estanques e nem nos exercícios propostos se tenta incentivar o estudante a compará-las. Há muito mais a preocupação em compará-las com o mundo contemporâneo do que compará-las entre si. 
As simplificações também podem, por vezes, adquirir um matiz valorativo, induzindo os alunos a fazer julgamentos de caráter ético sobre os acontecimentos históricos estudados, o que deve ser encarado com muita precaução por parte dos professores, uma vez que tais valorações dão margem à produção e/ou reprodução de estereótipos e, mais sério do que isso, à manutenção de preconceitos. Nesse sentido, é muito comum que os livros didáticos adotem explicações simplistas sobre fenomenos sociais bastante complexos, desqualificando a sua importância social. Assim é que a extrema religiosidade do povo egípcio é muitas vezes tomada como comodismo, já que na opinião dos autores é mais fácil aceitar-se a vida imposta pela religião do que explicá-la de outro modo. Em termos extremos, podemos nos deparar ainda com a seguinte observação a respeito das crenças dos povos primitivos: "como não conheciam as causas científicas do raio, apelavam, espontaneamente, para a fé, para as crenças". Diante de uma afirmação como essa, o pensamento religioso se converte em um tipo de explicação do mundo inferior à ciência.

Por último, devemos nos reportar às generalizações espaço-temporais, as quais costumam tomar a parte pelo todo, atribuindo a características particulares de sociedades circunscritas no tempo e no espaço uma abrangência e duração que não se verifica em termos empíricos, o que suprime as diferenças no interior do discurso histórico. Algo desse tipo ocorre quando nos deparamos com a seguinte afirmação: "Grécia e Roma foram as duas civilizaçñes da Antigüidade que mais utilizaram o trabalho de escravos, tanto nas cidades quanto nos campos". É preciso lembrar, nesse caso, que nem toda o mundo de fala grega se estruturou a partir do modo de produção escravista e que a difusão do escravismo em Roma foi um fenômeno restrito muito mais ao Ocidente.

Em flagrante contradição com a presença de tantas simplificações nos Livros Didáticos, percehemos que nos 
Manuais do Professor, os quais acompanham as coleções, aparecem citados e sugeridos para consulta por parte dos mestres diversos títulos atualizados em termos de História Antiga. Muitas vezes na própria bihliografia do Livro do Aluno são elencados títulos atualizados. Contudo, a função destes títulos parece ser muito mais a de enfeitar a obra, visto que o seu conteŕdo dificilmente é incorporado aos textos que integram o livro didático. Da mesma forma, buscando atender às modernas técnicas pedagógicas, os livros didáticos e os Manuais do Professor tentam incluir propostas de filmes, de livros paradidáticos e de sites a serem consultados na Internet. Todavia, dificilmente se elabora um roteiro para uso dos filmes propostos e alguns títulos apontados são de difícil aplicação, por exemplo, nas quintas séries. Os paradidáticos apontados muitas vezes são editados pela mesma editora do Livro Didático, o que nos revela muito mais uma estratégia comercial do que um cuidado estrito com a formação dos alunos. E os sites indicados se referem, quase sempre, a endereços eletrônicos de jornais e revistas de grande circulação e não a sites específicos de História Antiga, nos quais os alunos poderiam encontrar outras informações a respeito da Antigüidade (vide ROCHA, 1997).

Além dos equívocos de conteúdo propriamente ditos, são comuns no Livro Didático erros de datas e de legendas nas imagens as quais, na maioria das vezes, são apenas usadas para embelezar o livro, ou no máximo como uma confirmação do que é expresso no texto. Dificilmente, encontramos obras didáticas nas quais as ilustrações são exploradas como fontes históricas. Inclusive, várias vezes são usadas pinturas modernas ao se tratar da mitologia grega e romana. Desse modo, o que se apresenta ao aluno não são características dos deuses antigos, mas a releitura que o mundo moderno fez de seus atributos.

Muitos livros didáticos acabam por se caracterizar, não como um material de referência, mas como um caderno de 
atividades para expor, desenvolver, fixar e, em alguns casos, até avaliar o aprendizado (BRASIL, 2000, p. 20). Entretanto, nem nas atividades propostas sobre o mundo antigo impera a criatividade. Ainda se insiste na formulação de questionários, nos quais se avalia a memorização dos alunos, mais do que seu entendimento e interpretação dos conteúdos. São raras as obras didáticas nas quais se encontram exercícios que estimulem a criatividade dos estudantes, nos quais se exija, por exemplo, a sua opinião sobre os assuntos tratados. E, muitas vezes, quando tentam estimular o aluno a expressar a sua opinião, criam verdadeiros tribunais da História, em que as personagens históricas são julgadas pelas suas ações. Lembramo-nos de um livro didático no qual em cada capítulo a classe era incentivada a criar um verdadeiro tribunal na sala de aula, com advogados de defesa e de acusação para julgar as personagens citadas, como Júlio César, Cleópatra, Nero, Calígula, entre tantos outros já paradigmáticos. Em lugar de incentivar a compreensão da História, a disciplina é transformada, desta maneira, numa potência julgadora na qual imperam os juízos de valor e a transformação destas personagens históricas em verdadeiros esterétipos.

Diante de todos os problemas aqui apontados, o que poderia ser feito a fim de que pudéssemos saná-los, senão de imediato, ao menos em médio prazo? A opção mais rápida e cômoda seria, obviamente, suprimir o trabalho com o Livro Didático? Tal solução, no entanto, se revelaria uma boa saída? Cremos que não, uma vez que os Livros Didáticos têm a vantagem de encerrar, neles mesmos, um conjunto de informações, ainda que resumidas, que podem ser facilmente consultadas pelo aluno sempre que necessário, constituindo assim um valioso apoio para os conteúdos ensinados em classe. Por outro lado, é inegável que os nossos livros têm adquirido 
com o tempo uma tal qualidade gráfica que os torna em alguns casos irresistível para os alunos, especialmente os do Ensino Fundamental, não havendo razão para não se explorar o potencial imagético contido em tais obras quando se trata de ensinar História. No entanto, é imprescindível que o professor intervenha cada vez mais no processo ensino/aprendizagem, não se deixando seduzir nem tampouco limitar pelo Livro Didático. A relação, claro, deve ser fundada no respeito, uma vez que o Livro Didático é uma obra que possui um ou mais autores cujas idéias devem ser discutidas e não simplesmente desprezadas. No entanto, é necessário que o professor faça valer os seus anos de formação no sentido de dialogar com o Livro Didático, desafiá-lo, corrigir suas distorções, complementá-lo e, nesse processo, envolver os seus alunos, pois somente assim se formam as bases do conhecimento científico e da reflexão crítica.

Fazer isso com os conteúdos de História Antiga, no entanto, já ú um procedimento muito mais complicado, pois exige que o professor tenha tido uma melhor formação na área ou que tenha se dedicado ao estudo da disciplina por conta própria. Acqui, talvez, resida o nó górdio do problema, pois encuanto não formos capazes de produzir uma maior quantidade de especialistas em História Antiga não poderemos realizar nada verdadeiramente eficaz. Mas não basta apenas que formemos uma quantidade maior de especialistas. É preciso que estes não apenas encontrem espaço nos departamentos universitários, mas também dediquem um cuidado especial à graduação, tendo em vista que dificilmente un aluno voltará a ter contato com a disciplina após ter cumprido os seus créditos obrigatórios. Quando colocamos a questão nestes termos, percebemos o quanto ainda estamos longe de atingir condições de trabalho minimamente satisfatórias o que, no entanto, não deve nos desestimular. 
Na realidade, construir a História em sala de aula junto com os alunos não é uma tarefa fácil. O Brasil é um país regido por multiplicidades econômicas, culturais, regionais. E os livros didáticos também devem ser múltiplos, para responder a esta peculiaridade do nosso Pá́s. Entretanto, o que se espera é que o profession, ao usar um livro didático, tenha a certeza de ter em mãos um material minimamente adequado à sua tarefa de ensinar, contrihuindo assim para a real aprendizagem dos alunos. O livro didático de História, no fim das contas, deveria ser tão somente mais um instrumento de trabalho, entre tantos outros possíveis, no cotidiano das salas de aula brasileiras. Ele deveria ser uma fonte de consulta confiável e atualizada e também ser empregado como objeto de investigação, por meio do qual seus conteúdos fossem continuamente problematizados, tanto por alunos quanto por professores, e suas interpretaçôes dessacralizadas e expostas à crítica (LIMA, 1998, p. 205). Os alunos cobram a existência de um manual, os pais dos alunos demandam um roteiro de estudo para os filhos, e os professores, com baixos salários, e com muitos alunos e aulas a serem ministradas, submetem-se, muitas vezes por força das circunstâncias, ao conteúdo pronto e condensado nos livros didáticos. Muitos professores ainda se preocupam em procurar novas informações e novos exercícios para melhorarem suas aulas, mas para tanto costuma se valer de outros livros didáticos, o que acaba instituindo um círculo vicioso difícil de ser rompido. Como afirma Nicholas Davies (1996, p. 81), se o professor não tiver formação e condições financeiras e de exercício profissional adequadas, novos materiais ou linguagens poderão apresentar os mesmos problemas que o livro didático profissional. Tem-se que alterar conjuntamente os livros didáticos e a situação do professor. 


\section{Bibliografia}

BITENCURT, C. (Org.). O saber histórico na sala de aula. São Paulo: Contexto, 1997.

BORGES, V. P. et al. O ensino de história: revisão urgente. São Paulo: Brasiliense, 1986.

BRASIL. Ministério da Educação. Secretaria de Educação Fundamental. Programa Nacional do Livro Didático: histórico e perspectivas. Brasília, jan. 2000.

CARDOSO, C.F.S. et al. Modo de produção asiático: uma visita a un velho conceito. Rio de Janciro: Campus, 1990.

CARDOSO, C. F. S. A Cidade-Estado untiga. São Paulo: Ática, 1987.

CORASSIN, M. L. A Reforma agrária na Roma Antiga. São Paulo: Brasiliense, 1988.

DAVIES, Nicholas. O livro didático: apoio ao professor ou vilão do ensino de história. Cademos de Históric, Uberlândia, v. 6, n. 6, p. 81-85, 1996.

FINLEY, M. Escravidiü antiga e ideologia moderna. Rio de Janeiro: Graal, 1981.

- História antiga: testemunhos e modelos. São Paulo: Martins Fontes, 1994.

. Democracia antiga e modema. Rio de Janeiro: Graal, 1988.

FRANCO, M. L. O livro didático de História no Brasil. São Paulo: Global, 1982.

FREITAG, B. et al. O livro didático en questão. São Paulo: Cortez, 1989.

GIARLINA, A. (Org.) Ohomem romuno. Lisboa: Presença, 1992.

GUARINELLO, N. L. Imperiulismo Greco-Romano. São Paulo: Ática, 1987.

LE GOFF, J. História e memória. Campinas: Unicamp, 1994.

LIMA, S. C. F. de. O livro didático de história: instrumento de traballho ou autoridade "científica" ?. História e Perspectivas, Uberlândia, n. 18/19, p. 195-206, 1998. 
NADAI, E. O ensino de história no Brasil: trajetória e perspectiva. Revista Brasileira de História, São Paulo, 1993.

NIDELCOFF, M. T. A escola e a compreensão da realidade. São Paulo: Brasiliense, 1980.

RADUCH, M. C. Temas de história em livros escolares. Porto: Afrontamento, 1970.

ROCHA, I. E. 1000 sites de História Antiga e Arqueologia. São Paulo: Arte e Ciência, 1997.

SILVA, M. (Org.) Repensundo a história. Rio de Janeiro: Marco Zero, 1984.

VERNANT, J. P.; VIDAL-NAQUET, P. Traballho e escravidão na Grécia Antiga. Campinas: Papirus, 1989.

VEYNE, P. O inventúrio das diferenças. Lishoa: Gradiva, 1989.

ZAMBONI, E. (Org.). A prática do ensino de história. São Paulo: Cortez / CEDES, 1984.

\section{ABSTRACT:}

This article aims at discussing how the Ancient History is taught in some handbooks used by Brazilian students. Firstly, we realize an extreme breaking hetween the ordinary classroom and the University. So, the knowledge produced by the former is not systematically introduced in the latter. By reason of a problem like this, associated with the absence of experts in Ancient History during the making of the handbooks, the quality of the historical contents is very bad. The result is the perpetuation of several historical simplifications in the handhooks.

KEYWORDS: Ancient History, Class Book, Education. 